\title{
MULHERES E LUTA POR MORADIA MUDANÇAS NAS PRÁTICAS ASSOCIATIVAS NAS PERIFERIAS DE FLORIANÓPOLIS E LISBOA
}

\section{Women and struggle for housing Changes in associative practices in the peripheries of Florianópolis and Lisbon}

Francisco Canella

Programa de Pós-Graduação em Planejamento Territorial e Desenvolvimento Sócio-Ambiental - Universidade do Estado de Santa Catarina (UDESC)

Informações do artigo

Recebido em 22/08/2020 Aceito em 02/og/2020

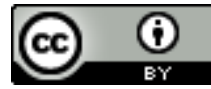

Esta obra está licenciada com uma Licença Creative Commons Atribuição 4.0 Internacional.

\section{Como ser citado (modelo ABNT)}

CANELLA, Francisco. Mulheres e luta por moradia Mudanças nas práticas associativas nas periferias de Florianópolis e Lisboa. Cadernos do CEAS: Revista

Crítica de Humanidades. Salvador/Recife, v. 45, n. 251, p. 658-674, set./dez., 2020. DOI: https://doi.org/10.25247/2447-861X.2020.n251.p658-674

\begin{abstract}
Resumo
O artigo tem por objetivo analisar as transformações em ocorridas em localidades surgidas de lutas por moradia em dois países. A partir de dados coletados no Brasil (no bairro Monte Cristo, em Florianópolis) e em Lisboa (na Cova da Moura, na área metropolitana de Lisboa), pretende-se identificar elementos que permitam a compreensão das transformações por que passaram as práticas associativas nessas localidades. Tendo como base a observação etnográfica e entrevistas com lideranças, a análise das duas localidades permitiu identificar alguns traços comuns, os quais são de fundamental importância para a elucidação do processo de reconfiguração territorial pelo qual passa a população dessas áreas no período decorrido entre a conquista da moradia e a consolidação de uma nova forma de produzir as suas condições de existência no bairro. De um lado, as mudanças nas práticas associativas, e de outro, a permanência da participação das mulheres nesses movimentos que envolvem a moradia.

Palavras-Chave: Movimentos sociais urbanos. Mulheres.
\end{abstract} Periferia urbana. Práticas associativas. Luta por moradia.

\section{Abstract}

This paper aims to analyze the changes that have occurred in localities arising from struggles for housing in two countries. Based on data collected in Brazil (in the Monte Cristo neighborhood, in Florianópolis) and in Lisbon (in Cova da Moura, in the metropolitan area of Lisbon), it is intended to identify elements that allow the understanding of the transformations that the associative practices have undergone in these places. Based on ethnographic observation and interviews, the analysis of the two locations allowed the identification of some common features, which have fundamental importance for the elucidation of the territorial reconfiguration process that the population of these areas goes through in the period between the conquest of housing and the consolidation of a new way of producing its conditions of existence in the neighborhood. On the one hand, changes in associative practices, and on the other, the continued participation of women in these movements that involve housing.

Keywords: Urban social movements; women; urban periphery; associatives practices; struggle for housing. 


\section{Introdução}

É comum localidades surgidas de lutas por moradia, cujos processos conflitivos exigiram forte organização coletiva dos moradores, trazerem como legado a intensa presença de suas práticas associativas no cotidiano do bairro. É o que apontam dados coletados no Brasil (no bairro Monte Cristo, em Florianópolis) e em Portugal ${ }^{1}$ (na Cova da Moura, na área metropolitana de Lisboa). Nas duas localidades de periferia foi possível identificar traços comuns em suas histórias, que permitem elucidar a dinâmica de reconfiguração territorial que se processou no período entre o surgimento das localidades (com as lutas pela conquista da moradia) e a consolidação do bairro. De um lado, uma significativa mudança nas formas de organização dos moradores (que pode ser descrito como um processo de desmobilização) acompanhado de uma tendência à privatização do cotidiano; de outro lado, relacionado também à dimensão público-privado, a participação das mulheres nesses movimentos que envolvem a moradia.

O fato de os bairros aqui analisados apresentarem características comuns não encobre a necessidade de reconhecer que se trata de duas realidades bastante distintas, envolvendo populações com diferentes culturas políticas, em países cujas histórias e tradições associativas guardam suas especificidades. Isso não impede, no entanto, que se tente estabelecer aproximações entre elas: pretendo aqui apontar a existência de alguns traços comuns às práticas, aos atores e às organizações cujas similaridades podem ser atribuídas a uma história comum de lutas em torno da questão da moradia. Tais aproximações podem ser o ponto de partida para a constituição de uma agenda investigativa que permita contrastar as particularidades de cada contexto específico, considerando as diferentes histórias e respectivas escalas. Não se trata, portanto, de igualar os dois contextos, pois há a clara consciência dos limites das conclusões desse trabalho, que se movimenta ainda num terreno marcado pela provisoriedade de suas hipóteses.

1 Os dados que sustentam esse artigo foram coletados através de observações etnográficas e entrevistas. No Brasil, na investigação de doutorado de Francisco Canella (2011) e no projeto de pesquisa Reconfigurações da segregação urbana: trabalho, moradia e pobreza na Grande Florianópolis (2017). Os dados referentes à realidade de Portugal, tomam por base as investigações desenvolvidas por Francisco Cuberos-Gallardo (2015), e complementados comas observações realizadas durante e estágio de pós-doutoramento. 


\section{As práticas associativas: suas histórias e o que mudou após a conquista da moradia}

O exame atento da história das mudanças que se processaram nas formas de organização e mobilização dessas duas localidades, tanto no caso brasileiro como no caso português, permite vislumbrar significados que se situam além da classificação simplista de desmobilização ou de perda de capacidade reivindicativa. Ao mesmo tempo, evidencia o papel das mulheres nessa dinâmica participativa, e sua importância no que se refere às mudanças nas cidades contemporâneas.

\section{A Cova da Moura}

A área em que se formou o bairro do Alto da Cova da Moura começou a ser habitada a partir dos anos 1970, período de expansão da área metropolitana de Lisboa. Um processo de crescimento acelerado fez surgir, de acordo com Luís Filipe Mendes (2008), um território densamente povoado e urbanisticamente desqualificado. O município de Amadora, onde se localiza o bairro, cresceu inicialmente com a vinda de migrantes do Alentejo e, posteriormente, com o processo de descolonização da África, assistiu à chegada de levas de portugueses retornados, angolanos, guineenses, moçambicanos e, principalmente, com cabo-verdianos.

Essa área vazia e subutilizada, localizada numa colina, onde se instalou tal população migrante (60\% de origem africana), situava-se próxima a uma área industrial, a qual demandava mão-de-obra barata e masculina. Muito perto da Cova da Moura, ao pé da Colina, uma estação ferroviária (parte da linha Lisboa - Sintra) possibilitava o acesso aos mercados da cidade, favorecendo trabalho das mulheres cabo-verdianas, que participavam da renda familiar com a venda de peixes nas ruas (CANELLA e GALLARDO, 2017, p. 136).

Sua população atual é de aproximadamente 6000 habitantes, numa área de colina distribuída em torno de 16,3 hectares. Tem sido alvo de vários projetos de intervenção urbanística, os quais não chegaram a alterar o seu traçado original , como observa Francisco Cuberos (2014, p. 8).

Nas lutas pelo bairro, a participação feminina foi notável: organizavam manifestações, encaminhavam abaixo-assinados para obtenção de água, luz e esgoto. Estiveram presentes na construção física do bairro. Inicialmente, na construção das casas (as "barracas"), no processo de autoconstrução conhecido como djunta-mon (o equivalente ao 
nosso mutirão). Embora tenham tido um papel subordinado aos homens, pois eram eles que atuavam como mestres de obras, reproduzindo uma hierarquia de gênero. Ficava reservado a elas o papel de força de trabalho adicional (CANELLA; CUBEROS, 2017, p.136). No entanto, cabe observar que essa condição de subordinação acaba passando por mudanças, a partir da própria reação das mulheres, como destacado em outro artigo:

\begin{abstract}
A pressão dessas mulheres imigrantes logo se tornaria evidente, ao conseguir que 0 processo de urbanização da área respondesse às suas necessidades e interesses. Não é por acaso que, em paralelo à instalação das barracas e à delimitação dos lotes, os primeiros sinais de auto-organização entre vizinhos apontam frequentemente para esses objetivos intimamente ligados à população feminina do bairro. (CANELLA; CUBEROS, 2017, p.136-137).
\end{abstract}

Em torno de questões como a água e o esgoto, os direitos das empregadas domésticas e a organização de uma pequena biblioteca, no início dos anos 1980 foi fundada a Associação Moinho da Juventude, que consistia numa Instituição Particular de Solidariedade Social (IPSS).

Tais iniciativas atendiam às demandas das mulheres. A biblioteca, por exemplo, não se resumia a um local de leitura, sendo também um espaço onde as mães podiam deixar seus filhos, liberando-as para o mercado de trabalho.

Na década de 1990 o bairro sofria com uma situação de crise: o desemprego no setor industrial e a não criação de outras oportunidades, o aumento do consumo e venda de drogas no bairro, os serviços públicos e os equipamentos precários prejudicavam a imagem do bairro, estigmatizado como área de pobreza e insegurança. Em reação a essa situação, jogou importante papel a Associação Moinho da Juventude, contando forte participação. A presença de uma imigrante belga, com experiência política e com formação acadêmica, e de seu marido, militante político vindo da Ilha da Madeira, foram fundamentais na criação dessa associação. A capacidade de articulação política do jovem casal, seus contatos com militantes de outros países, possibilitou a constituição de uma rede de apoio para obtenção de recursos para os projetos desejados para a Cova da Moura.

No 1989 que conseguimos o primeiro acordo com a Segurança Social para conseguir mais dinheiro. Para a construção da primeira sede, tivemos o apoio de voluntários da Bélgica, da Holanda, da Alemanha, para construir a sede. [...] É uma organização que são os Companheiros Construtores, que existe assim em vários países, e que vão a ajudar durante as férias: eles são os que pagam a sua viagem, e pois nós temos que dar de comer e dormida. E pois eles trabalham. [...] Fizemos também, em conjunto com a Trienal de Arquitetura, há três anos, houve um concurso sobre o 
bairro, para os arquitetos verem como é que é o bairro (Depoimento de Adele a Gallardo, 2013ele, In: CANELLA; GALLARDO, 2017, p. 140)

Por meio da Associação, foram firmados acordos de cooperação com a Segurança Social, o que permitiu a criação de creche, bem como de outros projetos sociais (com jovens, com idosos). As principais contratações para atuação nesses espaços que eram criados na Cova da Moura eram de mulheres. Assim, ao mesmo tempo que liberavam as mulheres para a procura de trabalho remunerado, também proporcionavam emprego no próprio bairro.

Assim, pode-se afirmar que a Cova da Moura escreveu (e ainda escreve) a sua história com o forte protagonismo das mulheres. Elas prosseguem à frente da lutas por melhoria do bairro, em campanhas de conscientização contra as drogas, na atuação nos projetos sociais e nas manifestações culturais. Sobre a área da cultura, é notável o envolvimento das mulheres nos grupos de dança e na organização do Kola San Jon, uma festa local que acontece anualmente, onde grupos com trajes típicos realizam uma procissão acompanhada de música e danças típicas. O reconhecimento do Kola San Jon como patrimônio imaterial português (ocorrido em 2014) foi um importante marco na reversão da imagem estigmatizadora do bairro.

\section{O Monte Cristo}

O bairro Monte Cristo atualmente aglutina cerca de 30 mil moradores, os quais se distribuem em 9 comunidades (é o termo empregado pelos moradores para se autodesignarem), cada qual com sua associação de moradores. Seu surgimento como bairro remonta aos anos 1980, quando passou a ser mais densamente povoado. Até então, essa área localizada junto à via expressa que liga a $\mathrm{Br}$-101 às pontes de acesso à parte insular de Florianópolis, era conhecida como Pasto do Gado. Como próprio nome indica, a área que servia como pastagem de gado era formada por terrenos privados e que pertenciam à COHAB, destinadas à moradia social.

Foi nessa década que passou a receber uma população migrante, na maioria provenientes da região Serrana (Lages e arredores) e do Oeste catarinense. A ocupação ocorreu em parte de forma espontânea, não organizada, mas também por meio de ocupações organizadas, cujas mobilizações eram promovidas pelo Centro de Apoio e 
Promoção do Migrante (CAPROM²). As primeiras ocupações aconteceram em 1990 (a Novo Horizonte e a Nova Esperança), e deram início a um intenso processo de organização dos moradores de todo o bairro (que então passava a se denominar Monte Cristo) na luta por equipamentos e serviços urbanos, pelo não despejo e pela regularização da moradia.

Esses movimentos foram bem sucedidos, construindo uma imagem de movimentos vitoriosos, consolidando conquistas para uma população historicamente excluída na cidade. Ao mesmo tempo, suas denúncias evidenciavam que a imagem de cidade que as elites locais procuravam construir sobre Florianópolis (expressa nos slogans "Ilha da Magia", "capital turística do Mercosul") se distanciava bastante de uma realidade que em muito se aproximava dos problemas de outras metrópoles.

Essas lutas tiveram como resultado um forte sentimento de pertencimento coletivo. A noção de comunidade (e é esse o termo pelo qual os moradores se auto denominam) adquiria o significado de "um conjunto articulado de pessoas, que discutiam e trabalhavam unidas na organização dos moradores" (CANELLA, 1992, p. 94).

Nos anos seguintes à conquista da moradia assistiu-se a um esvaziamento dos espaços coletivos de organização e de sociabilidade e, com eles do forte sentimento e união coletiva que tanto caracterizou o bairro em seus momentos de formação. No caso da Nova Esperança, a associação de moradores estava pouco ativa, nada representativa, e os momentos festivos e os espaços de lazer coletivo não mais existiam:

A rica dinâmica de sociabilidades, marcada por um claro componente político e utópico (como o emprego do termo comunidade expressava), não era mais ali encontrada no momento em que retomei contato com os moradores no final da década passada (anos 1990). Ao contrário, as sociabilidades estavam então marcadas pela desarticulação coletiva e pela privatização do cotidiano (CANELLA, 2011, p. 108).

Nas representações de muitos entrevistados, era estabelecido o contraste entre um presente de "privatização das relações" e um passado pleno de "articulações coletivas e projetos de transformação". Os relatos dos moradores e moradoras referiam-se ao medo, à violência e à criminalidade, distanciando-se daquelas narrativas que ressaltavam o ideal

2 O Centro de Apoio e Promoção do Migrante foi fundado por religiosos da Igreja Católica em 1985, tendo como objetivo atender os atingidos pelas enchentes no Vale do Itajaí que haviam migrado para a capital e a população de rua que já vivia nas ruas da área central da cidade. 
comunitário, disseminando uma autoimagem negativa entre as antigas lideranças e entre os moradores em geral. Para uma das mulheres que liderou as ações de ocupação de terreno que resultaram na Nova Esperança, a própria conquista da casa já fez com que muitos moradores abandonassem as vivências coletivas:

Ninguém chateou de sair lá da Coloninha. Morar sem água, sem luz, sem banheiro, sem nada, aqui era bem melhor. Mas muita gente disse: 'Lá na Coloninha nós éramos mais unido', e eu também gostava mais da Coloninha. Quando veio pra cá, muita gente começou a pensar muito em si. Aí teve muita divisão, todo mundo... lá em cima não parecia, assim, que você gostava do que era dos outros. Eu pra mim, eu achava que lá em cima todo mundo era igual, sabe? Mas depois que vim pra cá, não... muita divisão, é aquele que mais pode, que pode mais chora menos... é cada um por si e Deus por todos. Eu não sei se lá o pessoal era mais unido porque queria terra. O nosso projeto era ter a terra, né? (Depoimento de Janete, 2009, in: CANELLA; GALLARDO, 2017, p.143).

No entanto, deve ser observado que novas formas associativas tomavam lugar nessas localidades do bairro Monte Cristo, mesmo que convivendo com o sentimento de uma perda do passado de lutas, de um saudosismo com relação aos tempos marcados pela união coletiva: a forte presença de organizações não-governamentais, em parceria com a Universidade do Estado de Santa Catarina. Na Nova Esperança foram desenvolvidos projetos voltados para a geração de renda (envolvendo principalmente as mulheres), esporte e lazer e formação para o trabalho (voltados para a juventude), e cultura (grupo folclórico de boi-demamão, envolvendo toda a comunidade). Esses projetos partiram de uma antiga assessora do CAPROM que, tornando-se universitária, tomou a iniciativa de construir uma ampla rede de organizações sociais atuando em parceria no atendimento do conjunto de demandas acima citado.

Na comunidade Chico Mendes foi criada a Casa Chico Mendes, uma organização nãogovernamental que atua com a juventude local e que busca que articular os diferentes atores do bairro (organizações não-governamentais, associações de moradores, trabalhadores órgãos públicos que atuam diretamente com os moradores, como as creches, escolas e posto de saúde, entre outros), tornou-se bastante atuante, convertendo-se em referência na comunidade.

É importante destacar que nesse contexto, as práticas associativas no bairro deslocaram-se das associações de moradores (com suas subdivisões em comissões temáticas - cultura, infraestrutura, educação, saúde) para os projetos 
A crítica normalmente feita a esses projetos é que eles acabam substituindo o protagonismo das formas organizativas do período de lutas por moradia (cujo caráter era evidentemente mais político e reivindicativo, de confrontação como poder público. Tal mudança pode ser associada a um novo lugar político destinado às localidades pobres (ou às "comunidades"). Nas palavras de Joanildo Burity, trata-se de "políticas sociais focalizadas, compensatórias, cheias de condicionalidades e focadas no indivíduo e na família" (BURITY, 2006, p. 43). Uma concepção minimalista de Estado "empurrou" para a sociedade civil as responsabilidades sociais que antes eram obrigação do Estado. "Nessa concepção, os cidadãos devem fazer-se por seus próprios esforços particulares e a cidadania é cada vez mais equiparada à integração individual no mercado" (ALVAREZ; DAGNINO; ESCOBAR, 2000, p.16). É em tal contexto que entraram em cena os projetos elaborados e executados por atores que não os estatais, identificado sob o rótulo genérico de organizações nãogovernamentais Reconfigurando a vida cotidiana das famílias que vivem nas periferias, essa multiplicidade de projetos ingressou com força nas últimas décadas nessas áreas, fazendo com que o termo "projeto" fosse perfeitamente incorporado ao vocabulário nativo da população.

A percepção crítica desse processo não elimina o fato de que tais iniciativas, nos casos aqui analisados, não partiram de agentes externos às localidades, ou de atores paraestatais, protagonistas de políticas voltadas para parcerias com o chamado terceiro setor, mas resultou da ação dos próprios moradores, que buscaram articulações com órgãos públicos organizações do terceiro setor, universidades e agentes estatais (CANELLA, 2011, p. 247). Tanto na Cova da Moura como no Monte Cristo, antigas militantes da luta por moradia foram as protagonistas, agregando em torno de sua liderança um significativo grupo de mulheres. Assim, essas mudanças nas práticas associativas não podem ser dissociadas de outro traço significativo na dinâmica das localidades de periferia urbanas, que é a participação das mulheres.

\section{A participação das mulheres}

Nas duas realidades (Brasil e Portugal) a participação das mulheres não se resumiu aos períodos mais conflitivos de suas histórias (que correspondem ao surgimento das respectivas localidades); ao contrário, prosseguiu ao longo de suas histórias. Em Florianópolis, muitos 
visitantes caracterizavam a Nova Esperança como uma "comunidade de mulheres". As mulheres se fizeram ativas tanto na organização da ocupação e no enfrentamento com as autoridades como em reuniões de negociação, nos mutirões para construção das casas, na organização de eventos comunitários e nas organizações comunitárias.

No caso brasileiro, essas mobilizações aconteceram numa conjuntura nacional de ascensão de movimentos reivindicativos. A participação das mulheres se tornou mais evidente com os movimentos sociais que emergiram nos anos 1980, no contexto da redemocratização, no qual a sociedade brasileira assistiu à "entrada em cena de novos personagens" - para utilizar a expressão consagrada por Eder Sader (1988). Um conjunto bastante diversificado de atores políticos colocavam-se em movimento trazendo uma agenda de reivindicações que, para além de suas especificidades (relacionadas a temas como o acesso à terra e à moradia, as desigualdades étnico-raciais, o meio ambiente, os direitos humanos, a igualdade de gênero), lutavam para "redefinir o próprio sentido de noções convencionais de cidadania, representação política e participação", como colocam Alvarez, Dagnino e Escobar (2000, p. 16).

Eder Sader demonstrou em seu estudo como os clubes de mães, articulados por agentes pastorais da Igreja Católica, foram fundamentais na constituição das novas formas de organização, abrindo um espaço social para a mobilização coletiva, protegidos da repressão política, pois atuavam em espaços cotidianos, tidos como "não -políticos" (SADER, 1988, p. 199-225). Com isso, redimensionavam a relação entre o cotidiano e a política. Com isso criava-se no movimento popular, termo que definia ao conjunto de atores que vinham das periferias, e cujo ativismo tinha como base o local de moradia, fundamental para essa conjuntura de luta por direitos do período da redemocratização. Assim, ao analisarmos o engajamento das mulheres nos movimentos de luta por moradia deve-se considerar a existência de uma experiência histórica que se desenvolvia ainda durante o período militar. O movimento contra a carestia, de meados dos anos 1970, mobilizou principalmente donas de casa de bairros populares das cidades brasileiras.

Estudos como o de Roberta Neuhold (2009, p. 78-79), em São Paulo, e de Macedo Filho e Regino (2010), em Salvador, confirmam que as mulheres sempre foram maioria nos movimentos sem-teto e de moradia. Nesse sentido, a literatura sobre gênero e movimentos 
sociais urbanos ${ }^{3}$ ressalta o significado de proteção social que é incorporado à figura da casa. Em texto clássico, Elisabete Bilac, relacionava esse fenômeno ao ditado popular "quem casa quer ter casa" (1995, p. 29). Sendo o espaço doméstico aquele em que as mulheres transitam e reforçam seus laços, a casa passa a constituir um importante lugar simbólico para as mulheres. Em situações de separação conjugal, cabe às mulheres o cuidado dos filhos, fazendo da casa uma necessidade de primeira ordem. Desse modo, a luta por moradia, considerada nesse contexto de adversidades, não pode ser desvinculada dos esforços pela melhoria de vida (MACEDO, 2002, p. 66). Outro ponto que merece destaque refere-se à importância estratégica das mulheres nas ações coletivas que caracterizam as ocupações de terrenos ou nas mobilizações para evitar ações de despejo. Nos confrontos com forças policiais, é comum que as mulheres, acompanhadas de suas crianças, formem uma linha de frente, contendo as ações violentas das forças repressivas (MACEDO, 2002, p. 66). Ao fazerem isso, tais ações estratégicas (de fundamental importância para luta pela moradia), questionam a hierarquia entre os gêneros, colocando as mulheres no centro da cena política.

Além do mais, essa presença das mulheres com seus filhos contribui para desarmar a estigmatização das ocupações e das ações de resistência, trazendo um componente de humanidade às ações. Em contraposição aos qualificativos de "bandidos" ou "vagabundos", essas presenças conferem visibilidade ao drama social vivenciado pelas famílias pobres da cidade.

Assim, algumas autoras, como Teresa Kleba Lisboa (2002) analisam essa participação das mulheres pela perspectiva do empoderamento. Em seus estudos sobre as mulheres semteto em Florianópolis nos anos 1990, constatou que a migração do campo para a cidade acabou por reforçar as exclusões que já estavam submetidas. As novas desigualdades que passaram a vivenciar na cidade resultavam até mesmo em perdas cognitivas (LISBOA, 2002, p. 39), uma vez que os saberes anteriores pouca utilidade tinham no ambiente urbano. No entanto, com a participação na luta por moradia um novo sentido passou a ser atribuído à casa, passando essa a ser incorporada à "ordem dos desejos e a significar a realização dos sonhos" (LISBOA, 2002, p. 42), transcendendo a simples questão da necessidade material de

\footnotetext{
3 Importantes referências que devem ser mencionadas no debate acadêmico e político que se instaurou no país sobre a participação das mulheres são autoras como Elisabeth Souza-Lobo (1991), Céli Pinto (1992), Maria da Glória Gohn (1985, 2007), Fúlvia Rosemberg (1989) e Elisabete Bilac (1995).
} 
moradia. Desse modo, essa participação, na qual o fato de ser mulher fez toda diferença, representou uma significativa mudança nessas vidas tão marcadas por exclusões. Nessa mesma direção, o estudo de Marianne Moreira sobre ocupações recentes de sem-tetos no Rio de Janeiro demonstrou como, nessas situações conflitivas envolvendo a luta pela moradia, o lar se transforma em espaço de construção subjetiva, constituindo-se como lugar e território de construção identitária (MOREIRA, 2013, p. 119).

A dimensão de gênero presente nas lutas por moradia pode também ser articulada ao debate sobre as cidades. Saskia Sassen observa que a casa deve ser tomada como categoria analítica chave na compreensão de processos econômicos globais (SASSEN, 2003, p. 86). A autora refere-se às experiências transnacionais vivenciadas por migrantes nas periferias de muitas cidades europeias. Ao constatar a existência de dinâmicas específicas de gênero nas transformações do capitalismo contemporâneo, Sassen atribui a elas um papel estratégico: as mulheres migrantes, ocupadas em setores de serviços nas cidades globais seriam os equivalentes sistêmicos do proletariado periférico (SASSEN, 2003, p. 89). Uma vez que nesse contexto de reestruturação produtiva, no qual são desmantelados os direitos que regulavam as relações capital- trabalho, a força de trabalho das mulheres emerge como uma possibilidade de oferta capaz de mão de obra barata.

Essa perspectiva de Sassen, segundo suas própria palavras, "introduce de nuevo la comunidad y el hogar como espacios económicos importantes en las ciudades globales" (SASSEN, 2003, p. 91), reposicionando a comunidade e o lar, pode ser trazida para a realidade de países do capitalismo periférico. No caso do Brasil, com uma economia marcada pela informalidade e pela precariedade, nunca foi encontrada a mesma estabilidade das relações trabalhistas dos países do capitalismo central. Vera Telles evidencia em seus estudos, com uma das consequências das reconfigurações do capitalismo contemporâneo (TELLES, 2009), como no Brasil é cada vez maior o número de indivíduos e famílias colocados nas margens entre o legal e o ilegal, entre o formal e o informal. E isso pode estar reposicionando o lar e comunitário nas dinâmicas econômicas e associativas.

Os casos de Lisboa (Cova da Moura) e Florianópolis confirmam o quanto essa dinâmica nas comunidades periféricas analisadas se reflete nas relações de gênero. Essa participação feminina pode nessas circunstâncias de localidades periféricas e formadas por migrantes, pode corresponder a um traço distintivo mais geral. Hondagneu-Sotelo (1994), 
por exemplo, já ressaltava em sua análise das mulheres imigrantes mexicanas, o quanto elas são mais ativas na construção do ativismo comunitário.

O espaço da moradia, e o seu prolongamento nas atividades comunitárias locais, converte-se em espaço de atividades econômicas e espaço de existência pública das mulheres. Nessa articulação que encontra no bairro o seu espaço privilegiado de atuação, as mulheres passam a ocupar uma esfera intermediária entre a privada e a pública, a qual Albert Hunter (1985, p. 231-236) denominou esfera paroquial. Com isso, busca-se transcender aquelas categorias típicas do universo do pesquisador, tal como as de público e privado, superando análises dicotômicas. Nesse sentido, Antonádia Borges desenvolve sua análise sobre o significado da casa em duas realidades distintas (Brasil e África do Sul), nas quais as mulheres lutavam conta ameaças de despejo. Observa que as questões de gênero envolvidas em torno da casa "não se restringem a optar por uma entre duas alternativas bem estabelecidas - como o público ou o privado" (BORGES, 2013, p. 220). Em sua investigação, a autora constatou que às casas são dadas formas de vida não doméstica.

Mulheres como Sibongile, Gloria, Bruna ou Laudicéia estão experimentando em suas casas formas de vida não "domésticas" no sentido ordinário do termo. E, mais, não são em absoluto uma exceção. Através do trabalho político cotidianamente levado a cabo sob o teto de suas casas, a hospitalidade forjada se revela fruto de um esforço político em favor de uma convivialidade que não obedece os limites e separações modernistas do tempo e do espaço". (BORGES, 2013, p. 218)

As casas, segundo a autora, devem ser entendidas como espaços de circulação de muitas pessoas: elas "são para receber": "a hospitalidade forjada [em suas casas] se revela fruto de um esforço político em favor de uma convivialidade que não obedece os limites e separações modernistas do tempo e do espaço" (BORGES, 2013, p. 218).

A casa de uma das principais lideranças do bairro é marcada por essa indistinção, pois nela, na sua residência, não se apresenta uma rígida fronteira entre o público e o privado. $O$ mesmo pode ser dito com relação a uma das lideranças da Cova da Moura que tive a oportunidade de visitar.

O senso de coletividade se apresenta também na própria casa de Janete: chama a atenção a intensa circulação de pessoas da comunidade e de outras localidades do bairro Monte Cristo. São visitas constantes, em que circulam afetos, assuntos pessoais e preocupações comuns com os problemas do bairro. A sua casa tem um ar de provisório, pois tanto no pátio como no interior, ocupando alguns dos cômodos, há sempre um amontoado de objetos (materiais de construção, móveis, roupas doadas) que fizeram ou farão parte de atividades comunitárias. A aparente desorganização na verdade evidencia que a sua casa, além de moradia, é uma 
referência pública do bairro. Localizada na rua que dá acesso ao interior da comunidade, a casa de Janete faz parte do itinerário de agentes comunitários, pesquisadores, militantes de movimentos e assessores de ONGs que se dirigem ao bairro. O mesmo que ocorre na Cova da Moura, com a casa de Adele, referência para aqueles que chegam ao bairro, e ponto de parada obrigatório do cortejo do Kola San Jon (CANELLA; GALLARDO, 2017, p.144).

Procura-se, com isso argumentar a existência de uma sólida relação entre gênero e moradia, confirmada não só pelas correspondências verificadas entre diferentes realidades (Portugal e Brasil), mas também por experiências contemporâneas de luta por moradia, ocorridas em novos contextos sociais e históricos, as quais têm apresentado traços análogos aos de experiências passadas.

Nesse sentido, o recente movimento de luta por moradia que emerge na área metropolitana de Lisboa conta com forte presença das mulheres entre suas lideranças. A mesma participação é constatada em Florianópolis, onde novos ciclos de ocupação reacendem a luta por moradia em vários municípios da região metropolitana.

\section{Considerações Finais}

As duas localidades aqui analisadas, espaços que em dois diferentes países agregam moradores pobres, de origem migrante e que vivem em áreas segregadas de suas cidades, apresentam como característica comum as mudanças em práticas associativas e uma presença das mulheres nesses espaços de organização comunitária.

Um primeiro traço refere-se à natureza das novas práticas associativas que são desenvolvidas nessas localidades. A proliferação dos projetos sociais (o que acabou por esvaziar a participação as associações de moradores) está ligada à natureza das demandas que eles articulam, que são aquelas em que o atendimento da população local pelo Estado é precário ou mesmo inexistente Na Cova da Moura, a Associação Cultural Moinho da Juventude, consolidou-se relacionando questões identitárias e culturais com demandas voltadas para a geração de renda, para a criação de oportunidades de trabalho para os jovens, a educação e a assistência social (como a assistência aos idosos e creches). Da mesma forma, em diferentes localidades do bairro Monte Cristo (como a Nova esperança e a Chico Mendes), disseminaram-se projetos em torno dessas mesmas necessidades. Mais recentemente, a partir de 2015, foi formada uma Rede de Entidades (a partir da Casa Chico Mendes) tentando articular essa diversidade de experiências difundidas principalmente a partir de projetos 
encabeçados por organizações não-governamentais, mas sustentadas ou em conexão com lideranças do bairro. São experiências de diferentes naturezas, desde experiências pautadas pela auto-organização, herdadas do movimento dos sem-teto) até a ação de organizações não-governamentais, passando pela ação de grupos filantrópicos, atores paraestatais e movimentos culturais. Mais recentemente, um projeto envolvendo agricultura urbana, reciclagem de resíduos e geração de renda (a Revolução dos Baldinhos) conseguiu eleger um jovem vereador ${ }^{4}$.

Por trás desse novo "fazer (n)a cidade", e dos novos espaços de participação que emergem nessas localidades, encontra-se a significativa presença feminina. E aqui é possível apontar o segundo traço comum entre as duas localidades. Seja no Kola San Jon, ou em outras as práticas de auto-organização que ocorrem em torno de festas locais (como o boi de mamão em Florianópolis), ou no djunta-mon, ou nos mutirões que construíram muitas casas do Monte Cristo, seja em experiências voltadas para a geração de renda, ou nas associações de moradores, as mulheres ocuparam nesses bairros os principais espaços de articulações coletivas e de convívio social.

Na conclusão desse artigo é importante demarcar a temporalidade em que essa nova dinâmica participativa tem lugar. A partir dos anos 1990, a adoção de políticas de inclusão mais focalizadas, desenvolvidas a partir de organizações classificadas como terceiro setor, refletiu-se nas organizações que tinham por base de atuação o local de moradia, afetando os meios tradicionais de mobilização, como aqueles ancorados nas associações de moradores e nas mobilizações coletivas cujas reivindicações tinham como interlocutor agentes estatais. Nesse processo de mudança, a participação das mulheres continuou se fazendo presente, evidenciando uma trajetória contínua de engajamento, que se inicia nas lutas pela moradia, prossegue no período de formação das associações de moradores e se consolida nos projetos vinculados à vida cotidiana. A reconfiguração das ações coletivas não afetou a presença feminina nesses espaços locais. No Monte Cristo, o item mais apontado pelos moradores num questionário sobre as necessidades do bairro foi a creche - e a passou a ter nas mulheres a sua principal porta voz. A mesma prioridade na educação das crianças como

\footnotetext{
4 Em 2016 foi eleito o agrônomo Marcos Jose de Abreu, o Marquito. Embora não seja morador do bairro, sua eleição pode ser atribuída, entre outros fatores, ao sucesso dessa iniciativa desenvolvida no bairro Monte Cristo.
} 
uma necessidade básica encontra-se também na Cova da Moura. Nesse sentido, é possível pensar a partir de Sassen (2003) que a feminização de espaços de atuação nas periferias urbanas está relacionada às características assumidas pelas cidades na atual fase econômica mundial.

A presença das mulheres nessa fase em que projetos sociais, culturais e educativos ocupam a cena principal, envolvendo os atores locais, converte-se em elemento chave para a compreensão das cidades contemporâneas e suas periferias, tão marcadas pela informalidade e pela desregulamentação. Suas práticas apontam para um ativismo comunitário que politiza questões que, na vida dessas populações, eram restritas à ordem do privado. Essas reflexões, se conectadas à realidade cotidiana dessas localidades, pode contribuir na construção de espaços de resistência e de articulação coletivas.

\section{Referências}

ALVAREZ, Sonia; DAGNINO, Evelise; ESCOBAR, Arturo (org.). Cultura e política nos movimentos sociais latino-americanos: novas leituras. Belo Horizonte, Ed. UFMG, 2000.

BILAC, Elisabete Doria. Família: algumas inquietações. In: CARVALHO, Maria do Carmo Brant de (Org.). A família contemporânea em debate. São Paulo: Educ, 2003, p. 29-37.

BORGES, Antonádia. Mulheres e suas casas: reflexões etnográficas a partir do Brasil e da África do Sul. Cadernos Pagu, Campinas, n. 40, p. 197-227, jan./jun. 2013.

BURITY, Joanildo A. Cultura e identidade nas políticas de inclusão social. In: AMARAL Jr., Aécio. Inclusão social, identidade e diferença: perspectivas pós-estruturalistas de análise social. São Paulo: Annablume, 2006.

CANELLA, Francisco. Entre o local e a cidade: memórias e experiências de duas gerações de moradores da periferia urbana em Florianópolis (1990-2010). Tese (Doutorado em Ciências Sociais) - UERJ, Rio de Janeiro, RJ, 2011.

CANELLA, Francisco. A UFECO e o Movimento dos Sem-Teto: práticas instituintes nos espaços políticos da cidade. 1992. Dissertação (Mestrado em Sociologia Política) - Instituto de Filosofia e Ciências Humanas - Universidade Federal de Santa Catarina, Florianópolis, 1992.

CANELLA, Francisco; GALLARDO, Francisco José C. Mulheres e luta por moradia em Lisboa e Florianópolis, História Oral, v. 20, n. 2, p. 129-150, jul./dez. 2017 
CUBEROS, Francisco José. Cova da Moura: inmigración caboverdiana y asociacionismo en la periferia de Lisboa. AIBR: Revista de Antropología Iberoamericana, v. 10, n. 2, p. 177$202,2015$.

GOHN, Maria da Glória. A força da periferia: a luta das mulheres por creches em São Paulo. Petrópolis: Vozes, 1985.

GOHN, Maria da Glória. Mulheres - atrizes dos movimentos sociais: relações políticoculturais e debate teórico no processo democrático. Política \& Sociedade, Florianópolis, v. 6, n. 11, p. 41-70, out. 2007.

HONDAGNEU-SOTELO, Pierrett. Gendered transitions: Mexican experiences of immigration. Berkeley: University of California Press, 1994.

HUNTER, Albert. Private, parochial and public social orders: the problem of crime and incivility in urban communities. In: SUTTLES, Gerald D.; ZALD, Mayer N. (Ed.). The challenge of social control. Norwood: Ablex Publishers, 1985.

LISBOA, Teresa Kleba. Mulheres migrantes no sul do Brasil e seu processo de empoderamento. Revista Katalysis, Florianópolis, v. 5, n. 1, p. 12-26, 2002.

MACEDO FILHO, Renato; REGINO, Fabiane Alves. Mulheres, mães e movimento sem teto: o discurso maternalista e a construção da cidadania. In: SEMINÁRIO INTERNACIONAL FAZENDO GÊNERO, 9, 2010, Florianópolis. Anais..., 2010.

MACEDO, Márcia dos Santos. Relações de gênero no contexto urbano: um olhar sobre as mulheres. In: GTGÊNERO; PLATAFORMA CONTRAPARTES NOVIB (Org.). Perspectivas de gênero: debates para as ONGs. Recife: GTGênero; Plataforma de Contrapartes Novib; SOS Corpo Gênero e Cidadania, 2002. v. 1, p. 56-79.

MENDES, Luís Filipe. Urbanização clandestina e fragmentação socio-espacial urbana contemporânea: o Bairro da Cova da Moura na periferia de Lisboa. Revista da Faculdade de Letras - Geografia - Universidade do Porto. II Série, Volume II, 2008 - pp. 57-82.

MOREIRA, Marianna Fernandes. Mulheres sem-teto e a geografia da família: relações interdomésticas, gênero e reciprocidade. Espaço e Cultura, Rio de Janeiro, n. 34, p. 83-122, jul./dez. 2013.

NEUHOLD, Roberta dos Reis. Os movimentos de moradia e sem-teto e as ocupações de imóveis ociosos: a luta por políticas públicas habitacionais na área central da cidade de São Paulo. Dissertação (Mestrado em Sociologia) - USP, São Paulo, SP, 2009.

PIRES, R. Pena et al. Os retornados: um estudo sociográfico. Lisboa: I.E.D., 1987.

PINTO, Céli Regina. Movimentos sociais: espaços privilegiados da mulher enquanto sujeito político. In: COSTA, Albertina; BRUSCHINI, Cristina (Org.). Uma questão de gênero. São Paulo: Rosa dos Tempos; Fundação Carlos Chagas, 1992. p. 127-150. 
ROSEMBERG, Fúlvia. O movimento de mulheres e a abertura política no Brasil: o caso da creche-1984. In: Rosemberg, Fúlvia (Org.). Temas em destaque: creche. São Paulo:

Cortez; Fundação Carlos Chagas, 1989. p. 90-102.

SADER, Eder. Quando novos personagens entraram em cena. Rio de Janeiro: Paz e Terra, 1988.

SASSEN, Saskia. Contrageografías de la globalización: género y ciudadanía en los circuitos transfonterizos. Madrid: Traficantes de Sueños, 2003.

SOUZA-LOBO, Elizabeth. A classe operária tem dois sexos. São Paulo: Brasiliense, 1991.

\section{Detalhes do autor}

Francisco Canella

Doutor em Ciências Sociais, Professor do Programa de Pós-Graduação em Planejamento Territorial e Desenvolvimento Sócio-Ambiental - Universidade do Estado de Santa Catarina (UDESC). E-mail: franciscocanella@hotmail.com 